\title{
Direct oral anticoagulant treatment of deep vein thrombosis reduces IL-6 expression in peripheral mono-nuclear blood cells
}

\author{
SAVERIO CANDIDO ${ }^{1,2}$, GIOVANNI LUMERA ${ }^{3,4}$, GIULIANA BARCELLONA ${ }^{3,4}$, DAVIDE VETRI ${ }^{3,4}$, \\ ELDA TUMINO $^{3,4}$, INGRID PLATANIA ${ }^{3,4}$, EVELISE FRAZZETTO ${ }^{3,4}$, GRAZIELLA PRIVITERA ${ }^{3,4}$, \\ CARMELA INCOGNITO ${ }^{4}$, AGOSTINO GAUDIO ${ }^{3}$ and SALVATORE SANTO SIGNORELLI ${ }^{3,4}$
}

\author{
${ }^{1}$ Department of Biomedical and Biotechnological Sciences, Oncologic, Clinic and General Pathology Section; \\ ${ }^{2}$ Research Center for Prevention, Diagnosis and Treatment of Cancer; ${ }^{3}$ Department of Clinical and Experimental Medicine, \\ University of Catania; ${ }^{4}$ Internal Medicine Division, University Hospital ‘G. Rodolico', I-95123 Catania, Italy
}

Received September 16, 2020; Accepted October 21, 2020

DOI: 10.3892/etm.2020.9367

\begin{abstract}
Multiple factors play a pathophysiologic role for the venous thromboembolism (VTE) as a multi-factorial disease. Inflammation might play a peculiar role in shifting towards a pro-thrombotic state. Anticoagulant drugs are the first cure line for VTE. The low-molecular-weight heparins (LMWH) show anti-coagulant capability as well as reducing levels of inflammatory factors, including interleukin (IL)-6. The direct oral anticoagulants (DOACs) have shown efficacy in threating VTE, additionally to the anti-activated factor $\mathrm{X}$ these drugs seem able to reduce the abnormal release of pro-inflammatory agents. The present study evaluated the capability of DOACs in reducing plasma level of IL-6 in patients suffered from deep vein thrombosis (DVT) of the lower limbs. Our results showed reduced IL-6 expression levels in the peripheral lymphocytes of DVT compared to controls (fold-change, 2.8; $\mathrm{P}<0.05$ ). We postulate that lowered IL-6 expression in the lymphocytes of DVT patients may mediate the anti-inflammatory action of DOACs. The present study is the first evidence concerning the anti-inflammatory properties of DOACs in specific setting of VTE patients such as DVT.
\end{abstract}

\section{Introduction}

Venous thromboembolism (VTE) is a multi-factorial disease, and several findings have suggested that inflammation might play a role in shifting the hemostatic balance towards a pro-thrombotic state (1-4). Moreover, studies have demonstrated the frequency of VTE events in infected patients $(5,6)$. The most recent studies on patients infected by SARS-CoV-2 have shown high levels of D-dimer and fibrinogen-derived

Correspondence to: Professor Salvatore Santo Signorelli, Department of Clinical and Experimental Medicine, University of Catania, Via S. Sofia 78, I-95123 Catania, Italy

E-mail: ssignore@unict.it

Key words: deep vein thrombosis, inflammation, interleukin-6, direct oral anti-coagulant, therapy peptide (FDP) (7). Patients infected by SARS-CoV-2 were affected by very serious VTE events. Thus, VTE is closely linked to most inflammatory conditions. The role played by inflammation in promoting hyper-coagulation and counteracting systemic fibrinolysis seems crucial. The so-called 'cytokine storm' triggers excessive inflammation due to the bloodstream release of several pro-inflammatory cytokines (8). The role of leukocytes both in thrombus generation and vein remodeling has not yet been clarified (9), whereas pleiotropic interleukin (IL)- 6 and the development of thrombotic plugs in the venous circulation of the lower limbs (10) seem to play a crucial role. The hemodynamic disorders in venous circulation especially near venous valves, provoke hypoxia and oxidative stress, whereas several endogenous anticoagulants are expressed by intact endothelium (i.e., thrombomodulin, tissue factor pathway inhibitor, endothelial protein $\mathrm{C}$ receptor) (1). Leukocyte recruitment, adhesion receptor expression and tissue factor release initiate coagulation pathways (11-14). Therefore, activating the coagulation system is the main step in venous thrombosis, while the role of endothelium activation, as well as that of platelets, still require clarification. Concerning the role played by inflammation several studies demonstrated a key role of IL-6 in the development of deep vein thrombosis (DVT) in lower limbs $(15,16)$. Hypercoagulation is the main mechanism to be counteracted in treating patients with VTE, both DVT and PE. Here it is noted that PE has a high mortality risk, often the consequence of progressive, under-treated or undiagnosed and untreated DVT (17). Anticoagulant drugs are the first response in combating VTE and DVT. A number of factors (obesity, recent trauma, recent surgery, reduced mobilization, solid and non-solid cancer and genetic factors) have been listed as risk factors for DVT although the mechanisms involved in VTE are still under debate $(11,18,19)$. Low-molecular-weight heparins (LMWH) show concomitant anti-coagulant and anti-inflammatory activities reducing levels of inflammatory factors, including IL-6 (20). Recently, direct oral anticoagulants (DOACs) have demonstrated favorable results in combating VTE. DOACs showed anti-inflammatory capabilities in reducing the abnormal release of pro-inflammatory factors in addition to inhibiting the activation of factor $\mathrm{X}$ of the coagulation cascade (21-25). Our study focuses on the 
capability of DOACs in reducing plasma level of IL-6 in patients having DVT of the lower limbs.

\section{Patients and methods}

The potential anti-inflammatory activity of DOACs in 20 patients hospitalized with lower limb DVT was investigated. The patients were hospitalized at the Internal Medicine Unit of the Catania University Hospital 'Policlinico-Vittorio Emanuele' (Catania, Italy). In diagnosing DVT, we checked for compression of one or more lower limb veins (CUS test) and any echogenic material (thrombus) inside the veins. These DVT patients were initially assigned to the conventional therapy of LMWHs (5 days) and then treated with DOACs (Dabigatran $150 \mathrm{mg}$ daily, Edoxaban $60 \mathrm{mg}$ daily) from the sixth day. As controls, 22 healthy blood samples were obtained from previous case-control studies. Clinic, pathologic and demographic features and routine clinical biochemistry data were retrieved for each sample (Table I). The blood samples were drawn in the morning 5 days after patients started the DOAC therapy and after $12 \mathrm{~h}$ of fasting. All the patients supplied a blood sample 10 days after the starting of the DOACs drugs. Buffy coats were obtained by centrifuging ( $2000 \mathrm{x} \mathrm{g}$ for $10 \mathrm{~min}$ ) according to standard procedure. All the sampled patients were informed on the study and they gave their verbal consensus. Total RNA was extracted from the Buffy Coat samples using TRIzol ${ }^{\mathrm{TM}}$ LS reagent (cat. no. 10296028; Thermo Fisher Scientific, Inc.) according to the manufacturer's instructions. After treatment with DNase I RNase-free (cat. no. EN0525; Thermo Fisher Scientific, Inc.), $400 \mathrm{ng}$ of treated RNA (final concentration $20 \mathrm{ng} / \mu \mathrm{l}$ ) was converted into cDNA using the SuperScript ${ }^{\mathrm{TM}}$ IV Reverse Transcriptase kit (cat. no. 18090050; Thermo Fisher Scientific, Inc.) following the manufacturer's protocol. Then, $2.5 \mu \mathrm{l}$ of each cDNA underwent Real-Time amplification using Luminaris Color HiGreen qPCR Master Mix, high ROX (cat. no. K0362; Thermo Fisher Scientific, Inc.). The amplification of IL-6 and the GAPDH gene for reference, was performed with the 7300 Real-Time PCR System (Applied Biosystems; Thermo Fisher Scientific, Inc.) using the primer pairs reported as follows: forward (F): 5'-CACTGGCAGAAAACAACC TGA-3' and reverse (R): 5'-AGCTCTGGCTTGTTCCTC ACT-3' for IL-6 and F: 5'-AGAAGGCTGGGGCTCATTTG-3' and R: 5'-AGGGGCCATCCACAGTCTTC-3' for GAPDH. Thermal conditions: $50^{\circ} \mathrm{C}$ for $2 \mathrm{~min}$, followed by $95^{\circ} \mathrm{C}$ for $10 \mathrm{~min}$, and $40 \mathrm{cycles}$ of $95^{\circ} \mathrm{C}$ for $15 \mathrm{sec}, 60^{\circ} \mathrm{C}$ for $30 \mathrm{sec}$ and $72^{\circ} \mathrm{C}$ for $30 \mathrm{sec}$. The relative expression levels of IL-6 were obtained by the $2^{-\Delta \Delta C a}$ method (26).

The study was conducted in accordance with the Declaration of Helsinki, and the protocol was approved by the Ethics Committee of the Garibaldi Hospital (Catania, Italy; resolution n.23/2016/CECT2). Patients were informed about the objective of the study and were asked to give verbal informed consent to participate in it and to withdraw blood samples. All subjects gave their informed consent for inclusion before participating in the study.

Statistical analysis. Differential analyses were performed using the non-parametric Mann-Whitney test. Fisher's exact test was used to analyze the contingency table of the demo-
Table I. Demographic and clinicopathological characteristics of the samples.

\begin{tabular}{lccc}
\hline Characteristics & CTRL & DVT & P-value \\
\hline $\begin{array}{l}\text { Age (years), } \\
\text { median (range) }\end{array}$ & $48(41.7-62)$ & $56(46-71)$ & $0.2392^{\mathrm{b}}$ \\
Sex, no. (\%) & & & \\
$\quad$ Male & $12(54.5)$ & $12(63.15)$ & $0.76^{\mathrm{a}}$ \\
Female & $10(45.5)$ & $7(36.85)$ & \\
CRP, median (range) & $2.062(0.79-6.96)$ & $6(3-11)$ & $0.04^{\mathrm{b}}$ \\
\hline
\end{tabular}

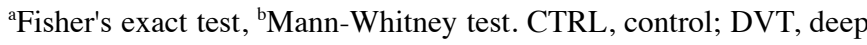
vein thrombosis; CRP, C-reactive protein.

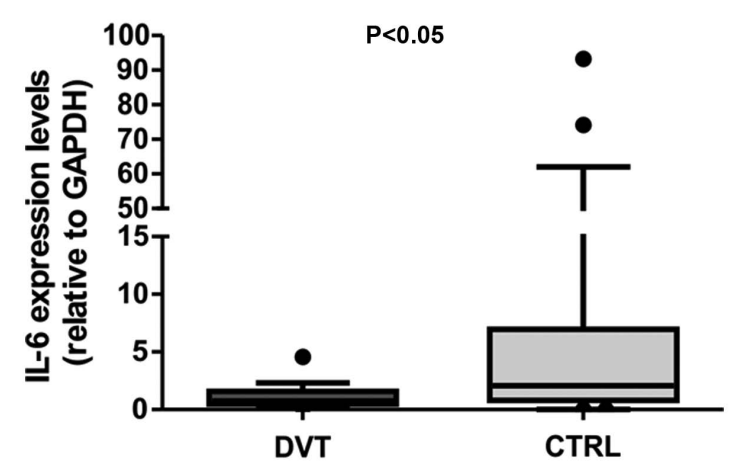

Figure 1. Expression levels of IL-6 in DVT samples and CTRL. IL, interleukin; DVT, deep vein thrombosis; CTRL, control

graphic and clinical-pathological characteristics. The analyses were performed using GraphPad Prism (GraphPad Software, Inc.). All experiments were performed in triplicate.

\section{Results}

Results of the study showed that IL-6 expression levels were statistically reduced in the peripheral lymphocytes of DVT patients compared to controls (fold-change, 2.8; $\mathrm{P}<0.05$ ) (Fig. 1). Despite C-reactive protein (CRP) levels being in the normal range $(<15 \mathrm{mg} / \mathrm{ml})$ for almost all samples, DVT patients showed higher CRP levels compared to normal samples $(\mathrm{P}<0.05$; Table I).

\section{Discussion}

Traditional knowledge on the pathophysiology of VTE consists of the three elements of Virchow's triad: endothelial injury, venous stasis and hypercoagulability (27). More data has been gathered on extending the pathophysiology of VTE (11). Damaged endothelium expresses adhesion receptors favoring the recruitment of leukocytes and platelets. Both bloodstream cell types seem to play a role in VTE $(12,28)$. Derived leukocyte products are able to activate coagulative cascade factors (factor X, XII) promoting intrinsic coagulative pathways. Inflammation correlates with activated coagulation because it influences the initiation and propagation of coagulation, it down-regulates physiological 
anticoagulant pathways and it inhibits fibrin removal (13). Activated coagulative factors via protease-activated receptors (PARs) may contribute to endothelial stress and exposure to adhesion molecules on the disarranged endothelial barrier leading to inflammation (29).

On VTE pathways, an interesting concept progressively emerged related to white blood cells (leukocytes and neutrophils) being rapidly attracted, and retained at the thrombosis site. Immuno-thrombosis is an interesting interaction between the innate immune system with the procoagulative condition (30). In particular, neutrophils can promote thrombosis by releasing neutrophil extracellular traps (NETs). NETs show several coagulative properties such as platelet activation, and fibrin string generation (31), whereas NETs are resistant to systemic fibrinolysis so they impair thrombus resolution $(32,33)$. In severe clinical conditions (i.e., acute sepsis), there is abundant expression of the ILs (e.g., IL-6) with high surface expression of the tissue factor. The relationship between inflammation and anti-coagulant balance is well known i.e. that combined tissue-factor activated factor VII converts factor $\mathrm{X}$ to activated factor, in turn activated factor $\mathrm{X}$ generates the activated factor II (thrombin) of coagulation. Reported evidence on the relationship between inflammation and the pro-coagulative activated pathway leads us to the conviction that inflammation must be considered as one of the most likely risk factors for VTE. Current approved guidelines for VTE (including DVT) therapy cite LMWH usage as first line (34). DOACs were initially approved for VTE prophylaxis in patients with favorable clinical conditions, to prevent the risk of deterioration in patients with VTE. Subsequently, DOACs have been also suggested in treating VTE. To date, DOAC therapy is currently assigned to VTE patients after discharge in preventing clinical worsening during follow-up. On the anti-inflammatory response caused by anti-thrombotic drugs, the anti-inflammatory effects of LMWHs were recently confirmed by reducing IL-6 and by the increased lymphocyte percentage found in patients infected by the COVID-19 virus (35). No specific anti-inflammatory effects have been reported for DOACs however, it could be reasonably expected that their potential anti-inflammatory effects could help in counteracting thrombin generation. In post-thrombotic syndrome, lower fibrinogen and inflammatory biomarkers were found in patients assigned to an anti-Xa activated oral drug (Rivaroxiban) compared to 5-7 days conventional treatment with LMWH and VKA (36). In conclusion, our results show lower levels of IL-6 in DVT patients assigned to DOACs compared to controls. Reduced IL-6 expression in the lymphocytes of DVT patients may mediate the anti-inflammatory action of DOACs. Anti-inflammatory activity has yet to be demonstrated in the LMWHs of patients with high inflammatory levels affected by acute dramatic thrombotic venous diseases as the consequence of SARS-CoV-2 infection. To the best of our knowledge, our study shows the first evidence concerning the anti-inflammatory properties of DOACs in DVT patients.

In conclusion, anticoagulant drugs such as LMWHs have demonstrated the direct potential of their anti-inflammatory capabilities in addition to their anticoagulant properties (37). Moreover, the involvement of inflammation in the pathophysiology of the venous thrombotic process has been clearly established (38). Inflammation is a very interesting tool for evaluating the potential of the new anti-thrombotic drugs (DOACs) targeted to inhibite or reduce inflammatory pathways. Overall, we are confident that these observations will contribute to clarifying the potential role of DOACs against the high inflammatory activity that is greatly responsible for favoring hyper-coagulation and in determining the clinical outcomes for DVT patients.

\section{Acknowledgements}

Not applicable.

\section{Funding}

No funding was received.

\section{Availability of data and materials}

The datasets used and/or analyzed during the current study are available from the corresponding author on reasonable request.

\section{Authors' contributions}

SC, GL, GB, DV, ET, IP, EF, GP, CI, AG and SSS: substantial contributions to conception and design, acquisition of data, analysis, and interpretation of data. Drafting the article, and revising it critically for important intellectual content. All authors read and approved the final manuscript.

\section{Ethics approval and consent to participate}

The study was conducted in accordance with the Declaration of Helsinki and was approved by the Ethics Committee of the Garibaldi Hospital (Catania, Italy; resolution n.23/2016/CECT2). All subjects gave their informed consent for inclusion before participating in the study.

\section{Patient consent for publication}

Not applicable.

\section{Competing interests}

The authors declare that they have no competing interests.

\section{References}

1. Mackman N: New insights into the mechanisms of venous thrombosis. J Clin Invest 122: 2331-2336, 2012

2. Branchford BR and Carpenter SL: The role of inflammation in venous thromboembolism. Front Pediatr 6: 142, 2018.

3. Riva N, Donadini MP and Ageno W: Epidemiology and pathophysiology of venous thromboembolism: Similarities with atherothrombosis and the role of inflammation. Thromb Haemost 113: 1176-1183, 2015.

4. Prandoni P: Links between arterial and venous disease. J Intern Med 262: 341-350, 2007.

5. Smeeth L, Cook C, Thomas S, Hall AJ, Hubbard R and Vallance P: Risk of deep vein thrombosis and pulmonary embolism after acute infection in a community setting. Lancet 367: 1075-1079, 2006.

6. Tichelaar YI, Kluin-Nelemans HJ and Meijer K: Infections and inflammatory diseases as risk factors for venous thrombosis. A systematic review. Thromb Haemost 107: 827-837, 2012. 
7. Tang N, Li D, Wang X and Sun Z: Abnormal coagulation parameters are associated with poor prognosis in patients with novel coronavirus pneumonia. J Thromb Haemost 18: 844-847, 2020.

8. Klok FA, Kruip MJHA, van der Meer NJM, Arbous MS Gommers DAMPJ, Kant KM, Kaptein FHJ, van Paassen J, Stals MAM, Huisman MV, et al: Incidence of thrombotic complications in critically ill ICU patients with COVID-19. Thromb Res 191: 145-147, 2020.

9. Saha P, Humphries J, Modarai B, Mattock K, Waltham M, Evans CE, Ahmad A, Patel AS, Premaratne S, Lyons OTA, et al: Leukocytes and the natural history of deep vein thrombosis: Current concepts and future directions. Arterioscler Thromb Vasc Biol 31: 506-512, 2011.

10. Phillippe HM: Overview of venous thromboembolism. Am J Manag Care 23: S376-S382, 2017.

11. Reitsma PH, Versteeg HH and Middeldorp S: Mechanistic view of risk factors for venous thromboembolism. Arterioscler Thromb Vasc Biol 32: 563-568, 2012.

12. Chirinos JA, Heresi GA, Velasquez H, Jy W, Jimenez JJ, Ahn E, Horstman LL, Soriano AO, Zambrano JP and Ahn YS: Elevation of endothelial microparticles, platelets, and leukocyte activation in patients with venous thromboembolism. J Am Coll Cardiol 45: 1467-1471, 2005

13. Levi M, van der Poll T and Büller HR: Bidirectional relation between inflammation and coagulation. Circulation 109: 2698-2704, 2004.

14. Franco RF, de Jonge E, Dekkers PE, Timmerman JJ, Spek CA, van Deventer SJ, et al: The in vivo kinetics of tissue factor messenger RNA expression during human endotoxemia: Relationship with activation of coagulation. Blood 96: 554-559, 2000.

15. Malaponte G, Polesel J, Candido S, Sambataro D, Bevelacqua V, Anzaldi M, Vella N, Fiore V, Militello L, Mazzarino MC, et al: IL-6-174 G > C and MMP-9-1562 C > T polymorphisms are associated with increased risk of deep vein thrombosis in cancer patients. Cytokine 62: 64-69, 2013.

16. Zhang Y, Zhang Z, Wei R, Miao X, Sun S, Liang G, Chu C, Zhao L, Zhu X, Guo Q, et al: IL (Interleukin)-6 contributes to deep vein thrombosis and is negatively regulated by miR-338-5p. Arterioscler Thromb Vasc Biol 40: 323-334, 2020.

17. Streiff MB, Agnelli G, Connors JM, Crowther M, Eichinger S, Lopes R, McBane RD, Moll S and Ansell J: Guidance for the treatment of deep vein thrombosis and pulmonary embolism. J Thromb Thrombolysis 41: 32-67, 2016.

18. Martinelli I, Bucciarelli P and Mannucci PM: Thrombotic risk factors: Basic pathophysiology. Crit Care Med 38 (Suppl): S3-S9, 2010.

19. Shaheen K, Alraies MC, Alraiyes AH, Christie R and Factor V: Leiden: How great is the risk of venous thromboembolism? Cleve Clin J Med 79: 265-272, 2012

20. Shiqing W, Shengzhong M, Cheng Z, Guangqing C and Chunzheng G: Efficacy of low molecular weight heparin in spinal trauma patients after part concentrated screw surgery and its influence on blood parameters and the incidence of deep venous thrombosis. Med Hypotheses 132: 109330, 2019.

21. Cirino G, Cicala C, Bucci M, Sorrentino L, Ambrosini G, DeDominicis G and Altieri DC: Factor Xa as an interface between coagulation and inflammation. Molecular mimicry of factor Xa association with effector cell protease receptor-1 induces acute inflammation in vivo. J Clin Invest 99: 2446-2451, 1997.

22. Borensztajn K, Peppelenbosch MP and Spek CA: Factor Xa: At the crossroads between coagulation and signaling in physiology and disease. Trends Mol Med 14: 429-440, 2008.
23. Bukowska A, Zacharias I, Weinert S, Skopp K, Hartmann C, Huth $\mathrm{C}$ and Goette A: Coagulation factor Xa induces an inflammatory signalling by activation of protease-activated receptors in human atrial tissue. Eur J Pharmacol 718: 114-123, 2013.

24. Esmon CT: Targeting factor Xa and thrombin: Impact on coagulation and beyond. Thromb Haemost 111: 625-633, 2014.

25. Kikuchi S, Tsukahara K, Sakamaki K, Morita Y, Takamura T, Fukui K, Endo T, Shimizu M, Sawada R, Sugano T, et al: Comparison of anti-inflammatory effects of rivaroxaban vs. dabigatran in patients with non-valvular atrial fibrillation (RIVAL-AF study): Multicenter randomized study. Heart Vessels 34: 1002-1013, 2019.

26. Livak KJ and Schmittgen TD: Analysis of relative gene expression data using real-time quantitative PCR and the 2(-Delta Delta C(T)) method. Methods 25: 402-408, 2001.

27. Kyrle PA and Eichinger S: Deep vein thrombosis. Lancet 365: 1163-1174, 2005.

28. Signorelli SS, Malaponte MG, Di Pino L, Costa MP, Pennisi G and Mazzarino MC: Venous stasis causes release of interleukin 1beta (IL-1beta), interleukin 6 (IL-6) and tumor necrosis factor alpha (TNFalpha) by monocyte-macrophage. Clin Hemorheol Microcirc 22: 311-316, 2000.

29. Kremers BMM, Ten Cate H and Spronk HMH: Pleiotropic effects of the hemostatic system. J Thromb Haemost 16: 1464-1473, 2018.

30. Brinkmann V: Neutrophil extracellular traps in the second decade. J Innate Immun 10: 414-421, 2018.

31. Fuchs TA, Brill A, Duerschmied D, Schatzberg D, Monestier M, Myers DD Jr, Wrobleski SK, Wakefield TW, Hartwig JH and Wagner DD: Extracellular DNA traps promote thrombosis. Proc Natl Acad Sci USA 107: 15880-15885, 2010.

32. Brill A, Fuchs TA, Savchenko AS, Thomas GM, Martinod K, De Meyer SF, Bhandari AA and Wagner DD: Neutrophil extracellular traps promote deep vein thrombosis in mice. J Thromb Haemost 10: 136-144, 2012

33. Savchenko AS, Martinod K, Seidman MA, Wong SL, Borissoff JI, Piazza G, Libby P, Goldhaber SZ, Mitchell RN and Wagner DD: Neutrophil extracellular traps form predominantly during the organizing stage of human venous thromboembolism development. J Thromb Haemost 12: 860-870, 2014.

34. Konstantinides SV, Meyer G, Becattini C, Bueno H, Geersing GJ, Harjola VP, Huisman MV, Humbert M, Jennings CS, Jiménez D, et al: 2019 ESC Guidelines for the diagnosis and management of acute pulmonary embolism developed in collaboration with the European Respiratory Society (ERS). Eur Heart J 41: 543-603, 2020.

35. Shi C, Wang C, Wang H, Yang C, Cai F, Zeng F, Cheng F, Liu Y, Zhou T, Deng B, et al: The potential of low molecular weight heparin to mitigate cytokine storm in severe COVID-19 patients: A retrospective cohort study. Clin Transl Sci: Sep 3, 2020 (Epub ahead of print).

36. Jeraj L, Jezovnik MK and Poredos P: Rivaroxaban versus warfarin in the prevention of post-thrombotic syndrome. Thromb Res 157: 46-48, 2017.

37. Bhalla V, Lamping OF, Abdel-Latif A, Bhalla M, Ziada K and Smyth SS: Contemporary meta-analysis of extended direct-acting oral anticoagulant thromboprophylaxis to prevent venous thromboembolism. Am J Med 133: 1074-1081.e8, 2020.

38. Borgel D, Bianchini E, Lasne D, Pascreau T and Saller F: Inflammation in deep vein thrombosis: A therapeutic target? Hematology 24: 742-750, 2019. 